\title{
Genetic information and life insurance
}

\author{
Robert J. Pokorski
}

\section{Genetic testing will become the future standard of medical care. Life insurers will also need access to genetic information if the insurance industry is to survive intact and if cover is to remain affordable.}

LIFE insurers are beginning to realize that genetic information is relevant to their assessments of mortality risk. If people use genetic tests to decide when to buy insurance and how much to buy, then insurers will also want to know the results of these tests.

But genetic tests may be difficult to interpret because of complex interactions between genes and the environment and variations in the age at onset and severity of disease. Doctors fear that patients will postpone genetic testing and thus miss the benefits of disease prevention and early diagnosis. There are also worries that insurers might use genetic information to invade privacy, discriminate against people with genetic diseases or deny insurance cover if genetic tests give unfavourable results.

My intention here is to show that genetics will become such an integral part of medical care that it will be impossible to draw meaningful distinctions between genetic and nongenetic information. Further, I argue that denying life insurers access to genetic information could lead to a fundamental restructuring of the life insurance industry and a drastic reduction in the number of people who could afford such cover.

\section{Genetic tests}

The US Institute of Medicine's Committee on Assessing Genetic Risks predicts that "multiplex genetic testing" will soon become routine clinical practice, with many genetic tests done on a sample of blood or other tissue. The committee foresees a time when the public will be offered genetic screening by walk-in testing and mail-order and home-test kits ${ }^{1}$.

The ability to monitor genetic evolution from health to disease will make obsolete the traditional pathological distinctions between metaplasia, dysplasia and cancer. Molecular biological tests will replace standard histological techniques. To a life insurance company, it makes no difference if a person has a pathological diagnosis of moderate-to-severe dysplasia or its genetic counterpart. In either case, there is a high risk of cancer developing in the near future.

The PCR (polymerase chain reaction) test has been used to detect exfoliated neoplastic cells in the stool of patients with colorectal neoplasms, in the sputum of patients with lung and head-and-neck cancer, in the blood, bile and stool of patients with pancreatic cancer and in the urine of patients with bladder cancer ${ }^{2,3}$. It will soon be common medical practice to use this DNA technology to diagnose genetic and nongenetic disorders in people who have developed a disease but are without symptoms. Distinctions between genetic and nongenetic information become even more blurred for tests that measure gene products ${ }^{1,4}$, including tumour markers such as prostate-specific antigen, and many common blood chemistry and haematological tests.

It is worth emphasizing here the distinction between predisposition and presymptomatic. If a genetic test identifies a predisposition to a disease, the disorder may or may not occur. By contrast a genetic test that detects a presymptomatic disorder identifies a condition that is already present but whose symptoms have not yet developed.

Many new forms of therapy will be based on genetic principles. As Henry Miller of the Institute for International Studies at Stanford University in California writes: "Somatic-cell human gene therapy applied to genetic defects, cancer, and cardiovascular disease may approximate in the first half of the next century what antibiotics have been in the second half of this century"5. Genetic testing will also be important in predicting the outcome of disease. For example, allelic loss from the long arm of chromosome 18 in patients with TNM stage II or III colorectal carcinoma has remarkable prognostic value ${ }^{6}$.

A list of common diseases with a genetic component now includes virtually every condition encountered in an average medical practice ${ }^{7}$. Information about family history, physical examinations and past treatment may also be seen as genetic ${ }^{1}$. Indeed, a report published in 1993 by the US National Center for Human Genome Research states that "[f]or policy purposes, it will become increasingly difficult to distinguish genetic from nongenetic diseases, and genetic information from non-genetic information" and goes on to observe that "[r]ecognizing that our genes affect many common diseases not previously thought of as genetic will transform the scope and meaning of terms such as genetic information, genetic test, asymptomatic condition, presymptomatic condition, and genetic predisposition to disease" ${ }^{\text {. Can insurers really }}$ be asked to ignore all this information because it is genetic in nature?

A fundamental principle of private life insurance is equity. Policy-holders with the same or similar risk of death are charged the same premium. By contrast, public life-insurance schemes operate on the principle of equality: everyone at a given level of income pays the same amount, subject to laws governing maximum age for contributions.

\section{Risk classification}

When people apply for life insurance, they are classified according to their expected mortality. The primary basis of risk classification is age. Yet in each age group the probability of death is greater for some people than others. Because of broad variation in life expectancy, all individuals in an age group cannot be offered private insurance on the same terms, so insurers use different mortality classifications. Most applicants worldwide are offered insurance at standard (average) rates, 2 to 3 per cent are charged a higher premium and 1 to 2 per cent are refused cover. (Despite the introduction of innumerable screening, diagnostic and therapeutic technologies over the past century, the percentage of people who have been able to obtain life insurance has in fact remained stable or increased.)

A private insurance system must retain the ability to identify the risks it is asked to insure (genetic or nongenetic), classify them into groups with similar expectations of loss and charge a price that reflects the level of risk posed by the group. This conclusion is supported by theories of private life insurance that have evolved over the past century, historical experience of assessment societies that collapsed because of failure to coordinate risk and premium, and basic economic principles.

Life insurance companies use both loss analysis and risk analysis when calculating premiums and determining the type of information needed to classify risks. Loss analysis looks at the past, and risk analysis looks at the present and into the future. Because the risk portfolios of all insurers already contain many policy-holders with genetic diseases, insurers would not be concerned if future purchasing decisions were based on previous buying practices, because these claims would be anticipated by loss analysis. This will not be the case once genetic testing becomes common medical practice, any more than it was with past medical advances that provided 
patients and insurance applicants with better information about their health and expected longevity. People will use genetic information to guide their insurance purchases. Life insurance companies will need access to the same information to classify the risks they are asked to accept in order to coordinate risk and premium.

Suggesting that genetic information should not be used to classify risks is tantamount to advocating a fundamental restructuring of the life insurance industry. The economic scope of such an undertaking would be immense. Large-scale cross-subsidies would be required between healthy and unhealthy policyholders. Premiums would become intolerably high for most people. To retain some semblance of today's private lifeinsurance mechanism, mandatory participation by all consumers would be required and the government would need to subsidize life insurance purchases of those unable to afford higher premiums.

Consumers would respond to a price increase in several ways. Some would buy less life insurance than if prices had remained the same, a reflection of the fact that insurance is a normal good, in an economic sense ${ }^{9}$. Others would decide to do without any protection because it would have become too expensive. Lowerincome families would probably be the most adversely affected: life insurance is viewed as one of the few available investment options for low-asset households ${ }^{10}$. Some people might buy the same amount of life insurance but have less money for mortgage payments, financial investments or insurance for medical expenses, disability income or long-term care. And people in the group with the highest mortality risk would probably buy much more life insurance than before. They have a remarkable economic incentive: a high claim expectation and low premium rate.

It would be impossible to predict the overall effect. But it seems safe to say that the percentage of people who could buy life insurance would not surpass today's high levels; lower-income applicants would be disproportionately affected; the total amount of life insurance purchased would decrease ${ }^{11}$; and policy-holders would have less money to spend on other things, as all economic costs are eventually paid for by individuals ${ }^{12}$.

Life insurance is inherently a 'discriminatory' product because premiums are based on differences in expected mortality rates. The differences are not intended to jeopardize basic rights but are necessary for actuaries to determine how much premium to collect to pay for future claims.

There is consensus in most countries that life insurers should not use race, ethnic background or religious preference in risk classification. Insurers have fully supported this position. But genetic information is different. Most genetic defects that cause disease in later life are probably not inherited but are acquired as somatic mutations (mutations acquired later in life through exposure to environmental carcinogens or errors in DNA replication or repair). There would be nothing unique about charging a higher insurance premium if cancer had developed because of genetic injury caused by cigarette smoke, ultraviolet light or some other environmental toxin. The same could be said for presymptomatic cancer tests of urine, stool or blood specimens, as most cancercausing mutations are somatic ${ }^{13}$.

Further, in the average patient (or insurance applicant) it will usually be impossible to determine if genetics or the environment dominated the disease process. There would also be unresolvable dilemmas in risk classification if genetic information were treated similarly to race, ethnic background or religious preference. If genetic tests were used to monitor the development of cancer, would applicants be treated differently if the cancercausing gene was inherited rather than the result of a somatic mutation? When genetic factors are identified that correlate with increased longevity ${ }^{14}$ or a lower risk of disease, will applicants with these favourable traits be told that this information cannot be used by insurers? Would a 30 -year-old man with a life expectancy of only 10 years be treated differently if genetic rather than environmental factors were responsible?

Fault or control is not a concern of life insurers, only relative mortality risk. For example, many insurance companies use cardiovascular risk factors to estimate the chance of premature coronary heart disease. If there were several unfavourable risk factors, the company's medical director would never consider whether the applicant was at fault or lacked control because of failure to exercise, maintain a normal weight or follow a healthy diet.

Practical distinctions between fault and control will lose much of their meaning as more genes are discovered. Genes can influence cardiovascular risk factors such as obesity ${ }^{15}$, hypertension ${ }^{16}$, hyperlipidaemia $^{17}$, diabetes mellitus ${ }^{18}$ and family history ${ }^{1}$. Because nicotine is clearly addictive $^{19}$, it may be only a matter of time before a genetic predisposition to the addictive effects of tobacco is discovered. Genes even play a role in alcohol and drug addiction ${ }^{20}$, two diseases often cited as examples of fault or lack of control. Insurers could not use fault or control in risk classification, nor could they restrict underwriting to situations where the applicant was thought to be at fault or in control. Most diseases are not a person's fault or under one's control. Exempting genetic diseases or information from risk classification would be equivalent to saying that applicants with all other disorders were responsible for their illnesses.
Genetic tests will be used to diagnose diseases that have already developed; most of these disorders (cancer and many chronic disorders for example) are not traditionally considered to be genetic in nature. In this instance, the tests can be viewed dispassionately as the latest in a series of new medical technologies intended to improve patient care. Concern about the use of genetic tests by life insurers is mostly irrelevant as the disorders genetic or nongenetic, overt or presymptomatic - are already present.

Other genetic tests screen for diseases that might develop in the future. These would be used by life insurers in a similar way to tests already used in the underwriting process. For example, individuals with normal or moderately increased serum cholesterol levels are offered insurance at average premium rates; some applicants with significantly increased levels are charged an extra premium; and a small percentage are refused cover because of markedly increased levels. Extra premiums are required only rarely even though abnormal cholesterol tests are common: underwriting is not based simply on an isolated cholesterol value but also on factors such as age, type of insurance and other cardiovascular risk factors.

Life insurers are genuinely interested in finding ways to use genetic information without jeopardizing the ability to obtain insurance. The risk classification system is not perfect but it does allow the vast majority of applicants to buy cover.

Robert J. Pokorski is at Swiss Re America, 60 Katona Drive, Suite 19, Fairfield, Connecticut 06430, USA. The opinions expressed here are not necessarily those of the organizations with which he is associated.

Assessing Genetic Risks: Implications for Health and Social Policy (eds Andrews, L. et al.) (National Academy Press, Washington DC, 1994).

2. Oliner, J. D. Scient. Am. Sci. Med. 16-25, September/October 1994

3. Hruban, R. H., Riet, P., Erozan, Y. S. \& Sidransky, D. New Engl. J. Med. 330, 1276-1278 (1994).

4. Kaback, M. J. Insur. Med. 25, 237-246 (1993)

5. Miller, H. I. Lancet 344, 316-317 (1994).

6. Jen, J., Kim, H. \& Plantadosi, S. New Engl. J. Med. 331 , 213-221 (1994)

7he Genetic Basis of Common Diseases (eds King, R. A. et al.) (Oxford University Press, 1992).

8. National Center for Human Genome Research Genetic Information and Health Insurance: Report of the Task Force on Genetic Information and Insurance (NIH Publications No. 93-3686, 1993).

9. Hammond, J. D., Houston, D. B. \& Melander, E. R. J. Risk Insur. 34, 397-408 (1967).

10. Heaten, R. S. \& Lee, I. F. J. Risk Insur. 41, 685 (1974)

11. Hoyt, R. E. J . Insur. Regul. 8, 304-315 (1990).

12. Keeney, R. L. New Engl. J. Med. 331, 193-196 (1994).

13. Breo, D. L. J. Am. med. Ass. 271, 1452-1454 (1994).

14. Rea, I. M. \& Middleton, D. J. Am. geriatr. Soc. $\mathbf{4 2}$, 978-983 (1994)

15. Zhang, Y., Proenca, R., Maffei, M., Barone, M., Leopold, L. \& Friedman, J. M. Nature 372, 425-432 (1994).

6. Williams, G. H. in Harrison's Principles of Internal Medicine (eds Isselbacher, K. J. et al.) Vol. 1. 1116-1131 (McGraw-Hill, 1994).

17. Marais, D. Cardiovas. J. S. Afr. 4, 7-9 (1994)

18. Blakeslee, S. New York Times 13 September1994.

19. Orleans, C. T. \& Slade, J. (eds) Nicotine Addiction: Principles and Management (Oxford University Press, 1993).

20. Mann, C. Science 264,1686-1689 (1994) 